\title{
Evolution of Susceptibilities of Helicobacter pylori Strains Circulating in Cameroon to Usual Antibiotics: A Three-year Study
}

\author{
Eyoum Bille Bertrant ${ }^{1,2}$, Tali Nguefak Lionel Danny ${ }^{1}$, Fotso Chimi Serge ${ }^{2}$, Malongue Agnes ${ }^{3,4}$, \\ Ateba Mbassa Roger ${ }^{2}$, Kuiate Jules Roger ${ }^{1}$, Kouitcheu Mabeku Laure Brigitte ${ }^{1, *}$ \\ ${ }^{1}$ Department of Biochemistry, Faculty of Science, University of Dschang, Dschang, Cameroon \\ ${ }^{2}$ Department of Diagnosis and Treatment Support, Laquintinie Hospital Douala, Douala, Cameroon \\ ${ }^{3}$ Department of Internal Medicine, General Hospital Douala, Douala, Cameroon \\ ${ }^{4}$ Department of Internal Medicine, Faculty of Medicine and pharmaceutical sciences, University of Douala, Douala, Cameroun
}

Email address:

laurebkouitcheu@yahoo.fr (K. M. L. Brigitte)

${ }^{*}$ Corresponding author

\section{To cite this article:}

Eyoum Bille Bertrant, Tali Nguefak Lionel Danny, Fotso Chimi Serge, Malongue Agnes, Ateba Mbassa Roger, Kuiate Jules Roger, Kouitcheu Mabeku Laure Brigitte. Evolution of Susceptibilities of Helicobacter pylori Strains Circulating in Cameroon to Usual Antibiotics: A Three-year Study. International Journal of Gastroenterology. Vol. 4, No. 2, 2020, pp. 63-71. doi: 10.11648/j.ijg.20200402.17

Received: October 9, 2020; Accepted: October 22, 2020; Published: November 19, 2020

\begin{abstract}
This study was conducted to estimate the evolution of antimicrobial susceptibilities of $H$. pylori strains isolated in Cameroon from 2014 to 2016 in relation to sociodemographic factors and clinical outcomes. A total of $278 \mathrm{H}$. pylori strains were isolated from patients with gastroduodenal disorders and tested for their susceptibility to nine antibiotics using the disc diffusion method. With time, a significant decreased of resistance was observed against clarithromycin (31.11 to $3.20 \%$, $\mathrm{p}<0.0001$ ), erythromycin ( 66.69 to $9.6 \%, \mathrm{p}<0.0001)$ and metronidazole ( 86.67 to $69.6 \%, \mathrm{p}<0.0001)$. Resistance to tetracycline ( 0 to $2.4 \%$ ) and doxycycline (0 to $1.6 \%$ ) slightly increase with time. Resistance to amoxicillin (95.5 to $94.4 \%$ ), ciprofloxacin (4.44 to $4 \%$ ) and levofloxacin ( 0 to $0.8 \%$ ) was relatively constant. No resistance was detected against rifampicin with the time. A significant decrease of resistance was detected against metronidazole / clarithromycin $(22.22$ to $1.6 \%, \mathrm{p}<0.0001)$ and amoxicillin / clarithromycin (26.67 to $3.2 \%, \mathrm{p}<0.0001)$. Among the tested isolates, 0.92 and $2.4 \%$ elicited triple resistance to metronidazole / tetracycline / amoxicillin in 2015 and 2016, and $0.8 \%$ quadruple resistance to metronidazole / tetracycline / clarithromycin / amoxicillin in 2016. Higher resistance rate was noticed as age increase and among female compared to men. Our data showed evolution in the antimicrobial susceptibilities of $H$ pylori strains circulating in our milieu with time. This finding highlights the need of monitoring periodically $H$. pylori resistance profile to antibiotics in order to determine the adapted treatment for this infection.
\end{abstract}

Keywords: Helicobacter pylori, Antibiotics, Resistance Evolution, Cameroon

\section{Introduction}

Peptic ulcer disease is a major public health problem because of its high prevalence, its complications and its cost. Since the discovery of Helicobacter pylori by Warren and Marshall in 1982 [1], peptic ulcer disease is mostly curable with a week's course of antibiotics and antisecretory drugs [2,3]. Regimen used in H. pylori eradication are triple and quadruple therapy $[4,5]$. Triple- therapy regimen consists of proton pump inhibitor and two antibiotics: amoxicillin and clarithromycin, or metronidazole and clarithromycin while quadruple therapy consists of proton pump inhibitor, bismuth and two antibiotics: amoxicillin plus clarithromycin, or metronidazole plus tetracycline $[4,5]$. Other treatments have also been proposed, including metronidazole, as well as tetracycline, fluoroquinolones, and rifamycins [4, 5]. However, these treatments, mainly because of resistance have become less effective. A recent study conducted 
throughout Europe shown that $H$. pylori resistance rates among adults were $17.5 \%$ for clarithromycin and $34.9 \%$ for metronidazole, and were significantly higher for clarithromycin and levofloxacin in Western/Central and Southern Europe $(>20 \%)$ than those in Northern European countries $(<10 \%)$ [6]. On the other hand, H. pylori resistance pattern within a particular population may varies with time. Resistance to metronidazole has increased from 26.7 to $47.2 \%$ in 2010 and 2015 respectively, while tetracycline resistance increased from 5.9 to $11.7 \%$ in the same period $(7,8)$. In the same way, resistance to clarithromycin has been found to increase from $17.2 \%$ in 2010 to more than $19.7 \%$ in 2017 [7-9].

In Africa, resistance rate to MET of $90 \%$ was found by Seck in Senegal [10], 100\% by Sherif et al. in Egypt [11], $56 \%$ by Chaabouni in Tunisia [12]. Against macrolides, resistance rate of 4 and $17.5 \%$ were found respectively in Egypt [11] and in Tunisia [12]. In Cameroon, resistance rate of $97.85 \%$ was found against MET [13]; 97.14 and $85.6 \%$ against amoxicillin respectively in 2018 and 2006; 13.57 and 44.7 against clarithromycin respectively in 2018 and 2006 [13, 14]. Taken into account this widespread emergency of MDR $H$. pylori strains, the Maastricht consensus meeting IV recommended a regular and periodical investigation of $H$. pylori resistance profile to the most commonly used antibacterial medications in different countries [15]. Epidemiological studies has reveal that the prevalence of this infection ranged from $92.2 \%$ to 64.34 respectively in 2004 and 2016 [16] in Cameroon. However, there is not data on the timely progression of $H$. pylori antimicrobial susceptibility in Cameroon. Therefore, the present investigation was aimed at determining the antimicrobial susceptibility progression of $H$. pylori strains isolated from 2014 to 2016 to nine routinely used antimicrobial agents in order to adopt an antibiotic regional Programs. The relationship between the resistance of $H$. pylori isolates with age, sex and endoscopic clinical outcomes was also examined.

\section{Methods}

\subsection{Sample Collection}

H. pylori isolates were recovered from gastric biopsies of patients with gastro-duodenal disorders undergoing endoscopy at Laquintinie Hospital and General Hospital both in Douala, Cameroon from August-2014 to December-2016. None of the patients had received neither antimicrobial therapy nor proton pump inhibitors for at least 2 weeks prior to endoscopy. The specimens that tested positive for urease test were placed in the sterile tubes containing 3-4 $\mathrm{ml}$ sterile normal saline for isolation within $4 \mathrm{~h}$.

\subsection{Isolation and Identification of H. Pylori}

The biopsies were ground and about two drops of homogenates were inoculated into supplemented Columbia agar (Columbia agar $+5 \%(\mathrm{v} / \mathrm{v})$ lacked horse blood and $1 \%$ (v/v) Vitox) for 48 to $72 \mathrm{~h}$ under microaerophilic conditions. The colonies gotten from this were identified using Gram staining and urease, oxidase, catalase reactions. Isolates that exhibited Gram negative curved rods and were positive for catalase, oxidase and urease tests were considered as $H$. pylori. The isolates were suspended in Eppendorf tubes containing Brain Heart Infusion broth supplemented with 5\% horse serum (BHI-serum) with 30\% glycerol and stored at $80^{\circ} \mathrm{C}$ until used.

\subsection{Antibiotic Susceptibility Test}

A total of $278 \mathrm{H}$. pylori isolates were recovered and submitted to the antibiotic susceptibility test using Kirby Bauer disk diffusion method (CLSI, 2015) [17]. The following antibiotic disks were tested: metronidazole $(50 \mu \mathrm{g}$, Bioanalyse), clarithromycin (15 $\mu \mathrm{g}, \quad$ Bioanalyse), erythromycin (15 $\mu \mathrm{g}$, Bioanalyse), amoxicillin (30 $\mu \mathrm{g}$, Himedia), ciprofloxacin (5 $\mu \mathrm{g}$, Mast diagnostics), levofloxacin $(5 \mu \mathrm{g}$, Mast diagnostics), tetracycline (30 $\mu \mathrm{g}$, Himedia), doxycycline (30 $\mu \mathrm{g}$, Mast diagnostics) and rifampicin ( $5 \mu \mathrm{g}$, Himedia).

All isolates were removed from storage at $-80^{\circ} \mathrm{C}$ and subcultured on supplemented Columbia Agar medium for two passages. $200 \mu \mathrm{l}$ of inoculum from 48 hour $H$. pylori colonies was prepared at Mac Farlands standard turbidity 3 $\left(6 \times 10^{8} \mathrm{CFU} / \mathrm{ml}\right)$ and used to seed supplemented Columbia agar plate. The discs of antibiotics were then placed and pressed on the inoculated agar surface. The place were then incubated at $37^{\circ} \mathrm{C}$ for 48 hours under microaerophilic conditions. Zones of lysis around the antibiotic discs were measured and the isolates were classified as sensitive or resistant according to the Microbiologist French Society guidelines [18]. The experiment was performed in triplicate and the mean diameters of inhibition zone recorded for each antibiotic was calculated.

\subsection{Statistical Analysis}

SPSS software, version 13 was used to perform statistical analysis. The significance of antibiotic resistance patterns between groups of patients according to socio demographic factors, clinical outcome was determined using Chi-square and Fisher's exact tests. Difference was considered statistically significant at $\mathrm{p}<0.05$.

\section{Results}

\subsection{Patients}

Among the 842 patients enrolled, 616 were $H$. pylori positive. From these positive patients, $278 \mathrm{H}$. pylori clinical isolates was recovered, 152 from women and 126 from men. Their mean age was $43 \pm 17$ years (range 15 to 60 years). Approximately thirty percent $(29.14 \%)$ of these subjects were with superficial gastritis, $25.54 \%$ with duodenal ulcers, $12.59 \%$ with erosive gastritis and $4.32 \%$ with gastric cancer. The characteristics of patient are summarized in Table 1. 
Table 1. Distribution of H. pylori isolates according patient's characteristic.

\begin{tabular}{ll}
\hline Variable & Number of isolates (\%) \\
\hline Sex & $152(54.68)$ \\
Female & $126(45.32)$ \\
Male & \\
Age & $95(34.17)$ \\
$\leq 20$ & $84(30.21)$ \\
$21-30$ & $75(26.97)$ \\
$31-40$ & $21(7.55)$ \\
$41-50$ & $3(1.08)$ \\
$51-60$ & \\
Endoscopic outcome & $71(25.53)$ \\
Duodenal ulcer & $37(13.31)$ \\
Gastric ulcer & $9(3.24)$ \\
Bulbar ulcer & $81(29.14)$ \\
Superficial gastritis & $35(12.59)$ \\
Erosive gastritis & $5(1.79)$ \\
Chronic gastritis & $12(4.31)$ \\
Gastric cancer & $25(8.99)$ \\
Normal endoscopic & $3(1.08)$ \\
Others & \\
Health facilities & $159(57.19)$ \\
HLD & $119(42.81)$ \\
HGD & 278 \\
\hline
\end{tabular}

HLD: Laquintinie Hospital Douala; HGD: General Hospital Douala; Others: Gastric polyp, Hiatus hernia, Ulcer scar, Cardiac incontinence etc.

\subsection{Culture and Susceptibility}

Out of the $278 \mathrm{H}$. pylori clinical isolates $261(93.9 \%)$ were resistant to amoxicillin, $11(3.85 \%)$ to ciprofloxacin, $3(2.4 \%)$ to levofloxacin, $30(10.75 \%)$ to clarithromycin, $96(34.5 \%)$ to erythromycin, $208(74.5 \%)$ to metronidazole, $4(1.4 \%)$ to tetracycline and $4(1.4 \%)$ to doxycycline. No resistance to rifampicin was detected (Table 2). Dual MET-AMX, METCLR, MET-TET, AMX-CLR, AMX-TET, CLR-TET resistance was seen in $204(73.38 \%), 17(6.11 \%), 4(1.44 \%)$, $26(9.35 \%), 4(1.44 \%)$ and $1(0.36 \%)$ isolates respectively. Simultaneous resistance to MET-TET-AMX was detected in 4 $(1.44 \%)$ cases. Quadruple drugs resistance for MET-TETCLR-AMX was seen in $1(0.36 \%)$ cases (Table 2$)$.

\subsection{Trends in Antibiotic Susceptibility Per Year}

In 2014 , out of the 45 isolates recovered, $95.56 \%$ (43/45) were resistant to amoxicillin, $4.44 \%$ (2/45) to ciprofloxacin, $31.11 \%(14 / 45)$ to clarithromycin, $86.67 \% \quad(39 / 45)$ to metronidazole and $66.67 \%(30 / 45)$ to erythromycin (Table 2). Dual resistance to MET-AMX, MET-CLR and AMX-CLR was seen in $38(84.44 \%), 10(22.22 \%)$ and $12(26.67 \%)$ isolates respectively (Table 2 ).

In 2015 , resistance rate of $92.59 \%(100 / 108)$ to amoxicillin, $3.70 \% \quad(4 / 108)$ to ciprofloxacin, $11.11 \% \quad(12 / 108)$ to clarithromycin, $75.92 \%(82 / 108)$ to metronidazole, $50 \%$ (54/108) to erythromycin, $1.85 \%(2 / 108)$ to levofloxacin, $0.92 \%(1 / 108)$ to tetracycline and $1.85 \%(2 / 108)$ to doxycycline was detected from the 108 clinical isolates recovered (Table 2). Dual resistance to MET-AMX, METCLR, MET-TET, AMX-CLR and AMX-TET was seen in 80 (74.07\%), 5 (4.63\%), 1 (0.92\%), $10(9.26 \%)$ and $1(0.92 \%)$ cases respectively. One case (1: $0.92 \%$ ) of resistance to METTET-AMX was detected (Table 2).

Table 2. Resistance pattern of Helicobacter pylori clinical isolates to antibiotics.

\begin{tabular}{|c|c|c|c|c|c|}
\hline \multirow{2}{*}{ Antibiotics } & \multirow{2}{*}{ Overall resistance $(\%) \mathrm{n}=278$. } & \multicolumn{4}{|c|}{ Resistance in isolates according to year, $\mathrm{N}(\%)$} \\
\hline & & $2014 n=45$ & $2015 n=108$ & $2016 n=125$ & P value \\
\hline AMX & $261(93.9)$ & $43(95.5)$ & $100(92.59)$ & $118(94.4)$ & 0.7443 \\
\hline Cip & $11(3.85)$ & $2(4.44)$ & $4(3.70)$ & $5(4)$ & 0.9906 \\
\hline CLR & $30(10.75)$ & $14(31.11)$ & $12(11.11)$ & $4(3.2)$ & $<0.0001^{*}$ \\
\hline LEV & $3(2.4)$ & 0 & $2(1.85)$ & $1(0.8)$ & l \\
\hline MET & $208(74.5)$ & $39(86.67)$ & $82(75.92)$ & $87(69.6)$ & $<0.0001 *$ \\
\hline TET & $4(1.4)$ & 0 & $1(0.92)$ & $3(2.4)$ & 1 \\
\hline ERY & $96(34.5)$ & $30(66.67)$ & $54(50)$ & $12(9.6)$ & $<0.0001^{*}$ \\
\hline DOX & $4(1.4)$ & 0 & $2(1.85)$ & $2(1.6)$ & I \\
\hline RIF & $0(0)$ & 0 & 0 & 0 & - \\
\hline MET-AMX & $204(73.38)$ & $38(84.44)$ & $80(74.07)$ & $86(68.8)$ & 0.1231 \\
\hline MET-CLR & $17(6.11)$ & $10(22.22)$ & $5(4.63)$ & $2(1.6)$ & $<0.0001^{*}$ \\
\hline MET-TET & $4(1.44)$ & 0 & $1(0.92)$ & $3(2.4)$ & I \\
\hline AMX-CLR & $26(9.35)$ & $12(26.67)$ & $10(9.26)$ & $4(3.2)$ & $<0.0001^{*}$ \\
\hline AMX-TET & $4(1.44)$ & 0 & $1(0.92)$ & $3(2.4)$ & I \\
\hline CLR-TET & $1(0.36)$ & 0 & 0 & $1(0.8)$ & I \\
\hline CLR-MET-LEV & 0 & 0 & 0 & 0 & I \\
\hline MET-TET-AMX & $4(1.44)$ & 0 & $1(0.92)$ & $3(2.4)$ & I \\
\hline MET-TET-CLR-AMX & $1(0.36)$ & 0 & 0 & $1(0.8)$ & 1 \\
\hline
\end{tabular}

P value comparing data per year, N: number, AMX: amoxicillin, Cip: ciprofloxacin, CLR: clarithromycin, LEV: levofloxacin, MET: metronidazole, TET: tetracycline, ERY: erythromycin, DOX: doxycycline and RIF: rifamycin. *: Significant.

In 2016, from the 125 clinical isolates recovered, $94.4 \%$ $(118 / 125)$ were found to be resistance to amoxicillin, $4 \%$ $(5 / 125)$ to ciprofloxacin, $3.20 \%(4 / 125)$ to clarithromycin, $69.6 \%$ $(87 / 125)$ to metronidazole, $9.6 \%(12 / 125)$ to erythromycin, $0.8 \%$ $(1 / 125)$ to levofloxacin, $2.4 \%(3 / 125)$ to tetracycline and $1.6 \%$
(2 / 125) to doxycycline (Table 2). Dual resistance to METAMX, MET-CLR, MET-TET, AMX-CLR, AMX-TET and CLR-TET was seen in $86(68.8 \%), 2(1.6 \%), 3(2.4 \%), 4$ $(3.2 \%), 3(2.4 \%)$ and $1(0.8 \%)$ isolates respectively. Simultaneous resistance to MET-TET-AMX was seen in 3 
(2.4\%) cases and quadruple drugs resistance to MET-TETCLR-AMX in $1(0.8 \%)$ cases (Table 2).

\subsection{Overall Evolution of Resistance from 2014-2016}

A decreasing resistance rate from $31.11 \%$ to 3.20 , from $66.69 \%$ to $9.6 \%$ and from 86.67 to $69.6 \%$ was observed against CLR $(\mathrm{p}<0.0001)$, ERY $(\mathrm{p}<0.0001)$ and metronidazole $(\mathrm{p}<0.0001)$. Resistance to TET ( 0 to $2.4 \%)$ and DOX (0 to $1.6 \%)$ slightly increase from 2014 to 2016 . Resistance to amoxicillin (95.5 to $94.4 \%$ ), ciprofloxacin (4.44 to $4 \%$ ) and levofloxacin ( 0 to $0.8 \%$ ) was relatively constant with time. No resistance was detected against RIF with the time (Figure 1 and Table 2).

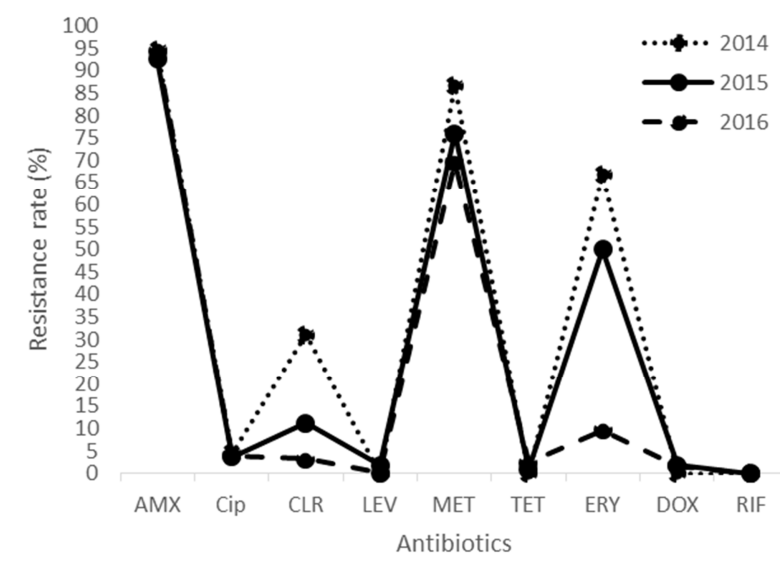

Figure 1. Resistance of Helicobacter pylori to the tested antibiotics according to year (2014-2016).
A significant linear decrease of dual resistance was detected against MET-CLR and AMX-CLR with resistance rate decreasing from 22.22 to $1.6 \%$ and from 26.67 to $3.2 \%$ respectively $(\mathrm{p}<0.0001$ and $\mathrm{p}<0.0001$ respectively) (Table 2 and 3, Figure 1). In 2014, no case of triple or quadruple resistance were detected, whereas in 2015 and 2016, 0.92 and $2.4 \%$ cases of resistance to MET-TET-AMX was detected and $0.8 \%$ to MET-TET-CLR-AMX in 2016 (Table 2).

\subsection{Factors Associated with Antibiotic Resistance}

Increasing age was significantly associated with ERY $(\mathrm{p}=0.038)$ and DOX $(\mathrm{p}=0.0001)$ resistance (Table 4). The resistance frequencies to $\operatorname{LEV}(\mathrm{p}=0.0001)$, CLR $(\mathrm{p}=0.013)$ and ERY $(p=0.043)$ was significantly associated with endoscopic outcome with a high resistance rate among patients with bulbar ulcer and gastric cancer for CLR, gastric ulcer and chronic gastritis for ERY. CLR ( $\mathrm{p}=0.0001)$, MET $(p=0.018)$ and ERY $(p=0.0001)$ resistance were all significantly higher in subjects enrolled at HLD compared to those from HGD (Table 4).

A significantly higher resistance rate among female compared to men was detected against MET-AMX ( $\mathrm{p}=0.001)$. Also, significant increase of resistance rate to MET-AMX was noticed as age increase $(p=0.026)$. Again, subjects enrolled at HLD compared to those from HGD were significantly more resistant to AMX-MET $(\mathrm{p}=0.002)$ (Table $4)$.

Table 3. Resistance rates of H. pylori clinical isolates according to gender, age and clinical outcome.

\begin{tabular}{|c|c|c|c|c|c|}
\hline \multirow{2}{*}{ Variables } & \multirow{2}{*}{ Number of isolates } & \multicolumn{4}{|c|}{ Antibiotic resistance rate N (\%) } \\
\hline & & AMX & CIP & CLR & LEV \\
\hline \multicolumn{6}{|l|}{ Gender } \\
\hline Female & 152 & $142(93.4)$ & $8(5.3)$ & $17(11.2)$ & NA \\
\hline Male & 126 & $119(94.4)$ & $3(2.4)$ & $13(10.3)$ & $3(2.4)$ \\
\hline \multicolumn{6}{|l|}{ Age } \\
\hline$\leq 20$ & 95 & $90(94.7)$ & $6(6.3)$ & $7(7.41)$ & $1(1.1)$ \\
\hline $21-30$ & 84 & $79(94.0)$ & $4(4.8)$ & $10(11.9)$ & NA \\
\hline $31-40$ & 25 & $72(96.0)$ & $1(1.3)$ & $12(16.0)$ & $2(2.7)$ \\
\hline $41-50$ & 21 & $17(81.0)$ & NA & $1(4.8)$ & NA \\
\hline $51-60$ & 3 & $3(100)$ & NA & NA & NA \\
\hline \multicolumn{6}{|l|}{ Endoscopic outcome } \\
\hline Duodenal ulcer & 71 & $69(97.2)$ & $4(5.6)$ & $8(11.3)$ & NA \\
\hline Gastric ulcer & 37 & $34(91.9)$ & NA & $4(10.8)$ & NA \\
\hline Bulbar ulcere & 9 & $9(100)$ & NA & $4(44.4)$ & NA \\
\hline Superficial gastritis & 81 & $75(92.6)$ & $4(4.9)$ & $4(4.9)$ & $2(2.5)$ \\
\hline Erosive gastritis & 35 & $33(94.3)$ & $1(2.9)$ & $3(8.6)$ & NA \\
\hline Chronic gastritis & 5 & $5(100)$ & NA & NA & NA \\
\hline Gastric cancer & 12 & $10(83.3)$ & $1(8.3)$ & $4(33.3)$ & NA \\
\hline Normal endoscopic & 25 & $23(92.0)$ & $1(4.0)$ & $2(8.9)$ & NA \\
\hline Others & 3 & $3(100)$ & NA & $1(23.3)$ & $1(33.3)$ \\
\hline \multicolumn{6}{|l|}{ Health facilities } \\
\hline HLD & 159 & 149 (93.7) & $6(4.2)$ & $26(16.4)$ & $2(1.3)$ \\
\hline HGD & 119 & $112(94.1)$ & $5(3.8)$ & $4(3.4)$ & $1(0.8)$ \\
\hline Overall & 278 & $261(93.9)$ & $11(3.85)$ & $30(10.75)$ & $3(2.4)$ \\
\hline
\end{tabular}


Table 3. Continued.

\begin{tabular}{|c|c|c|c|c|c|}
\hline \multirow{2}{*}{ Variables } & \multicolumn{5}{|c|}{ Antibiotic resistance rate $\mathbf{N}(\%)$} \\
\hline & MET & TET & ERY & DOX & RIF \\
\hline \multicolumn{6}{|l|}{ Gender } \\
\hline Female & $118(77.6)$ & $3(2.0)$ & $53(34.9)$ & $3(2.0)$ & NA \\
\hline Male & $90(71.4)$ & $1(0.8)$ & $43(34.1)$ & $1(0.8)$ & NA \\
\hline \multicolumn{6}{|l|}{ Age } \\
\hline$\leq 20$ & $72(78.8)$ & $1(1.1)$ & $24(25.3)$ & NA & NA \\
\hline $21-30$ & $59(70.2)$ & $3(3.6)$ & $32(38.1)$ & $3(3.6)$ & NA \\
\hline $31-40$ & $57(76.0)$ & NA & $29(38.9)$ & NA & NA \\
\hline $41-50$ & $17(81.0)$ & NA & $11(52.4)$ & NA & NA \\
\hline $51-60$ & $3(100)$ & NA & NA & $1(33.3)$ & NA \\
\hline \multicolumn{6}{|l|}{ Endoscopic outcome } \\
\hline Duodenal ulcer & $54(76.1)$ & NA & $28(39.4)$ & $1(1.4)$ & NA \\
\hline Gastric ulcer & $29(78.4)$ & $1(2.7)$ & $19(51.4)$ & $1(2.7)$ & NA \\
\hline Bulbar ulcere & $6(66.7)$ & NA & $4(44.4)$ & NA & NA \\
\hline Superficial gastritis & $62(76.5)$ & $3(3.7)$ & $22(27.2)$ & $1(1.2)$ & NA \\
\hline Erosive gastritis & $25(71.4)$ & NA & $11(31.4)$ & NA & NA \\
\hline Chronic gastritis & $5(100)$ & NA & $3(60)$ & $1(20.0)$ & NA \\
\hline Gastric cancer & $8(66.7)$ & NA & $5(41.7)$ & NA & NA \\
\hline Normal endoscopic & $18(72.0)$ & NA & $3(12.0)$ & NA & NA \\
\hline Others & $1(33.3)$ & NA & $1(33.3)$ & NA & NA \\
\hline \multicolumn{6}{|l|}{ Health facilities } \\
\hline HLD & $127(79.9)$ & $3(1.9)$ & $87(54.7)$ & $3(1.9)$ & NA \\
\hline HGD & $81(68.1)$ & $1(0.8)$ & $9(7.6)$ & $1(0.8)$ & NA \\
\hline Overall & $208(74.5)$ & $4(1.4)$ & $96(34.5)$ & $4(1.4)$ & $0(0)$ \\
\hline
\end{tabular}

AMX: amoxicillin, Cip: ciprofloxacin, CLR: clarithromycin, LEV: levofloxacin, MET: metronidazole, TET: tetracycline, ERY: erythromycin, DOX: doxycycline, RIF: rifampicin, HLD: Laquintinie Hospital Douala; HGD: General Hospital Douala; Others: Gastric polyp, Hiatus hernia, Ulcer scar, Cardiac incontinence etc, NA: not available.

Table 4. Factors associated with antibiotic resistance pattern.

\begin{tabular}{|c|c|c|c|c|c|}
\hline Resistance pattern & Pvalue & Resistance pattern & Pvalue & Resistance pattern & P value \\
\hline AMX & & ERY & & AMX-CLR & \\
\hline Gender & 0.462 & Gender & 0.435 & Gender & 0.369 \\
\hline Age & 0.135 & Age & 0.164 & Age & 0.383 \\
\hline Outcome & 0.642 & Outcome & 0.102 & Outcome & 0.224 \\
\hline Health facilities & 0.549 & Health facilities & 0.436 & Health facilities & 0.469 \\
\hline CIP & & DOX & & AMX-TET & \\
\hline Gender & 0.180 & Gender & 0.499 & Gender & 0.725 \\
\hline Age & 0.280 & Age & $0.038^{*}$ & Age & 0.294 \\
\hline Outcome & 0.691 & Outcome & $0.043 *$ & Outcome & 0.153 \\
\hline Health facilities & 0.546 & Health facilities & $0.0001 *$ & Health facilities & 0.726 \\
\hline CLR & & MET-AMX & & CLR-TET & \\
\hline Gender & 0.728 & Gender & 0.385 & Gender & 0.682 \\
\hline Age & 0.134 & Age & $0.0001 *$ & Age & 0.282 \\
\hline Outcome & $0.013 *$ & Outcome & 0.087 & Outcome & 0.082 \\
\hline $\begin{array}{l}\text { Health facilities } \\
\text { LEV }\end{array}$ & $0.0001 *$ & $\begin{array}{l}\text { Health facilities } \\
\text { MET-CLR }\end{array}$ & 0.426 & $\begin{array}{l}\text { Health facilities } \\
\text { CLR-MET-LEV }\end{array}$ & 0.304 \\
\hline Gender & 0.092 & Gender & $0.001 *$ & Gender & 0.222 \\
\hline Age & 0.463 & Age & $0.026^{*}$ & Age & 0.465 \\
\hline Outcome & $0.0001 *$ & Outcome & 0.116 & Outcome & 0.211 \\
\hline Health facilities & 0.608 & Health facilities & 0.002 & Health facilities & 0.367 \\
\hline MET & & MET-TET & & MET-TET-AMX & \\
\hline Gender & 0.147 & Gender & 0.353 & Gender & 0.231 \\
\hline Age & 0.526 & Age & 0.468 & Age & 0.080 \\
\hline Outcome & 0.577 & Outcome & 0.423 & Outcome & 0.379 \\
\hline Health facilities & $0.018^{*}$ & Health facilities & 0.127 & Health facilities & 0.275 \\
\hline TET & & & & MET-TET-CLR-AMX & \\
\hline Gender & 0.385 & & & Gender & 0.266 \\
\hline Age & 0.300 & & & Age & 0.374 \\
\hline Outcome & 0.535 & & & Outcome & 0.557 \\
\hline Health facilities & 0.426 & & & Health facilities & 0.336 \\
\hline
\end{tabular}

AMX: amoxicillin, Cip: ciprofloxacin, CLR: clarithromycin, LEV: levofloxacin, MET: metronidazole, TET: tetracycline, ERY: erythromycin, DOX: doxycycline, RIF: rifampicin *: Significant. 


\section{Discussion}

The emergence of MDR H. pylori strains has become a serious challenge all over the world, as it is the major reason for the low rate of $H$. pylori eradication and the failure of the therapies both in developing $[18,20]$ and developed countries $[21,22]$. This highlights the need for knowledge on the resistance pattern and their timely progression in order to adopt an antibiotic regional Programs. In the present investigation, we evaluated the evolution of antimicrobial susceptibilities of $278 \mathrm{H}$. pylori clinical isolates from Cameroon during a 3-years period (2014 to 2016).

In this study, $93.9 \%$ of the tested isolates were resistant to amoxicillin with the resistance rate fluctuation of 95.5 to $94.4 \%$ during the study period, indicating a constant high resistance to this drug. This observation is in line with previous studies in Cameroon, showing $H$. pylori high resistance rate of 85.6 and $97.14 \%$ respectively in 2006 [14] and 2018 [13]. This high resistance rate to amoxicillin could be the consequence of the wide use of this antibiotic in Cameroon due to its cheapness. Similar reports were noticed in Japan where the authors detected a stable trend of resistance to amoxicillin in their sample isolates with time [23]. However, it is in contrast with some studies revealing an increase trends of primary resistance to amoxicillin in South Korea [24] and a decrease rate from 7.9 to $0 \%$ among Bulgarian children in 1996-1999 and 2005-2008 [25].

Resistance rate of $10.75 \%$ and $34.5 \%$ respectively against clarithromycin and erythromycin was detected among our sample isolates (Table 2). We also found a significant decrease of resistance against CLR $(p<0.0001)$ and ERY $(p<0.0001)$ during the 3 year study. Similar resistance trend to clarithromycin is observed when putting together previous reports regarding resistance to this antibiotic in Cameroon. In fact, resistance rate to CLR of $44.7 \%$ and 13.57 was found respectively in 2006 and 2018 in Cameroon [13, 14]. High cost of clarithromycin limits its use in our milieu [26], this may partially explained such decrease in the resistant rate of the tested isolates to this drug. Our results showed a simultaneous decrease of resistance to both clarithromycin and erythromycin with the time, this may be due to crossresistance in this class of antimicrobials as previously described [13]. Some data on the timely variability of the susceptibility of this pathogen to macrolides are available in the literature. A stable resistance trend to clarithromycin has been reported in UK and a decrease one in Netherlands, where antibiotic sailing is lower than in others EU countries $[27,28]$. Also in Sweden where national antibiotic use is lower, low $H$. pylori resistance rate of $1.0-1.5 \%$ to clarithromycin had been noticed [29]. Owing to the growing consumption of macrolides, $H$. pylori resistance has increased in many countries [30]. Increasing macrolide use for pulmonary, ear, nose and throat infections in Japan has been associated with growing clarithromycin resistance from $18.9 \%$ to $27.7 \%$ respectively between $2002-2003$ and 2004 -
2005 [23]. Similarly, increase resistance rate has been reported against macrolide in Italy (2.1-fold over 15 years) [25], in Bulgaria (1.8-fold over 10 years) [25], in South Korea (4.9-fold over 10 years) [24] and in Japan (1.5-fold over 2 years) [23]. In South Korea, the primary clarithromycin resistance rate increasing from 0 to $13.8 \%$ in 1987 and 2003 has been reported [31]. In Bulgaria, the primary clarithromycin resistance increase of 10\% from 1996 to 1999 and $18.4 \%$ from 2005 to 2008 was observed, probably owing to an increase in the national consumption of macrolides from 0.8 daily doses per 1000 inhabitants in 2004 to 1.8 daily doses per 1000 inhabitants in $2006[32,33]$.

Our findings showed resistance rate of $74.5 \%$ against metronidazole and a significant decrease of resistance to the said antibiotic with time $(\mathrm{p}<0.0001)$. Previous reports in Cameroon regarding resistance to MET did not shown a similar resistance trend to this antibiotic. In fact, resistance rate of 93.2 and $97.85 \%$ respectively was revealed in 2006 and 2018 [13, 14], suggesting little or no variation of the resistance against this drug. This high resistance is thought to be linked to the frequency of use of nitroimidazole derivatives in the treatment of digestive and genital parasitic infections [34]. Primary $H$. pylori resistance to metronidazole are reported to be stable in countries such as Bulgaria [24], Japan [23] and The Netherlands [27], unlike in South Korea where an increase resistance rate due to growing use or abuse of metronidazole for parasitic or female genital infections has been reported [31].

Resistance to tetracycline is not widespread. Low rates of $0.3,1.7$ and 2\% were detected respectively in Sweden [35], Estonia [36] and Lebanon [37], which are slightly in accordance with the resistance rate of $1.4 \%$ detected in this study. Although tetracycline were slightly affected by resistance, low increasing of TET and DOX resistance from 0 to $2.4 \%$ and 0 to $1.6 \%$ respectively was detected in our milieu. In Cameroon, resistance rate of 43.9 and $2.86 \%$ had been reported in 2006 and 2018 [13, 14], suggesting a drastic decrease of resistance to tetracycline from this time elapsed. However, our result as regard resistance rate to TET is similar to that reported in 2018 , thus the differences between these resistance trends probably reflect the variation in tetracycline usage between our sample populations. Increasing primary $H$. pylori resistance to tetracycline has been described in South Korea and a stable one in Bulgaria due to decreasing tetracycline consumption from more than 4.2 daily doses per 1000 inhabitants in 1994-1999 to 2.4 daily doses per 1000 inhabitants in 2006 [24, 31].

Although no resistant to fluoroquinolones has been early observed in Cameroon [13], this study showed low resistance rate of $3.85 \%(11 / 278)$ and $2.4 \%(3 / 278)$ respectively against ciprofloxacin and levofloxacin. Our results also showed that resistance to levofloxacin ( 0 to $0.8 \%$ ) and ciprofloxacin (4.44 to $4 \%$ ) was relatively constant from 2014 to 2016 , which is seem to be similar to that observed in Bulgaria [24]. However, increasing resistance trend to levofloxacin of 5.1-fold in children and 4.2-fold in adults since 2004 was observed in 
Taiwan $[38,39]$, whereas in South Korea it was ranged from 0 to $33.3 \%$ from 1987 to 2003 [31].

Regarding multi-drug resistance pattern, our finding showed that $75 \%$ of the isolates were resistant to at least two antibiotics, which is in accordance with the $70 \%$ previously reported in Cameroon [13]. This high prevalence of MDR phenotype among $H$. pylori isolates circulating in Cameroon may be attributed to the exhaustive use of antibiotics across the country. Dual resistance to MET-AMX, MET-CLR, METTET, AMX-CLR, AMX-TET and CLR-TET was detected among the isolates with a significant decrease against METCLR and AMX-CLR. In contrast, increasing double resistance rates to MET-CLR from 2.8 to $3.1 \%$ and from 5.0 to $11.2 \%$ had been observed at two centers in the UK, and a stable resistance pattern in Bulgaria [40]. Also, Pereira et al. in their study detected two clinical isolates with resistance to MET-CLR and three to metronidazole-clarithromycinciprofloxacin simultaneously [41]. Resistance rate range from 0 to $0.92 \%$ and to $2.4 \%$ was detected against METTET-AMX respectively in 2015 and 2016 and $0.8 \%$ against MET-TET-CLR-AMX in 2016, indicating an increase of simultaneous resistance with time. Few studies reporting similar low quadruple-drug resistance rate from India $(2.5 \%)$, Bulgaria (0.7\%), Vietnam (1.9\%), and Indonesia (2.6\%) has been documented [24, 42, 43]. However, these resistance rate were lower than the 15.71 and $5.71 \%$ triple and quadruple drugs resistance reported in Cameroon [25] and the $37.9 \%$ reported in Chile [42].

Our data also showed a significantly higher resistance rate against AMX-MET among female compared to men $(\mathrm{p}=0.001)$. Study conducted in Costa Rica [44] and Mexico [45] also reported similar distribution of resistance to MET according to sex. The widespread use of this antibiotic by women for gynecological infections may explained such observation [34]. Our results also showed a high resistant rate among older compare with younger $(\mathrm{p}=0.026)$, may be due to the fact that increase in age enhance the chance of exposure to resistance strains.

\section{Conclusion}

The present study showed that the resistance patterns of $H$. pylori isolates from Cameroon has changed within the 3 years study. Our data showed significant decrease in resistance of $H$ pylori isolates against CLR, ERY and MET, a slightly increase of resistance to TET and DOX, stable state of resistance to amoxicillin, ciprofloxacin and levofloxacin, and a significant decrease of dual resistance against METCLR and AMX-CLR from 2014 to 2016 in our milieu. Women and older were the groups showing higher resistance rates to antibiotics. Increasing resistance rates to TET and DOX should be considered as an indicator of abuse and overuse of these antibiotics that ultimately limit their effectiveness for future generations. Even though the resistance to CLR and MET is decreasing, it continues to be worryingly high. Therefore, the frequency of $H$. pylori resistance to current antibiotics should be monitored periodically to determine the adapted treatment for this infection.

\section{Abbreviations}

HLD: Laquintinie Hospital Douala, HGD: General Hospital Douala, AMX: amoxicillin, Cip: ciprofloxacin, CLR clarithromycin, LEV: levofloxacin, MET: metronidazole, TET: tetracycline, ERY: erythromycin, DOX: doxycycline, RIF: rifamycin.

\section{Author Contributions}

Kouitcheu Mabeku LB designed the work; Fotso CS, Malongue A and Ateba MR examined the patients, collected patient's clinical data and biopsies sample; Eyoum BB and Tali NLD carried out the analysis; Kouitcheu Mabeku LB and Kuiate JR analyzed the data and wrote the paper.

\section{Declarations}

All the authors do not have any possible conflicts of interest.

\section{Acknowledgements}

We acknowledge the support of the staffs of the Laquintinie Hospital and General Hospital of DoualaCameroon who facilitated recruitment of patients for this research. We thank the participating patients for their cooperation.

\section{References}

[1] Warren JR, Marshall B. Unidentified curved bacilli on gastric epithelium in active chronic gastritis. The Lancet. 1983; 321: 1273-1275.

[2] Conférence de Consensus. Maladie ulcéreuse et gastrite à l'heure de Helicobacter pylori. Conclusions et recommandations du jury. Gastroenterol Clin Biol. 1996; 20: S155-162.

[3] Malfertheiner P, Megraud F, O'Morain C, Hungin APS, Jones $\mathrm{R}$, Axon DY, et al. Current concepts in the management of Helicobacter pylori infection. The Maastricht 2000 Consensus Report. Aliment Pharmacol Ther. 2002; 16: 167-80.

[4] Hunt R, Xiao S, Megraud F, Leon-Barua R, Bazzoli F, van der Merwe S, Coelho LV, et al. Helicobacter pylori in developing countries. World Gastroenterol Organ Global Guidelines. 2010; $1-15$.

[5] Gisbert JP, Molina-Infante J, Amador J, Bermejo F, Bujanda L, Calvet X, et al. IV Spanish Consensus Conference on Helicobacter pylori infection treatment. Gastroenterología y Hepatología (English Edition). 2016; 39: 697-721.

[6] Megraud F, Coenen S, Versporten A, Kist M, Lopez-Brea M, Hirschl AM, et al. Helicobacter pylori resistance to antibiotics in Europe and its relationship to antibiotic consumption. Gut. 2012. 
[7] De Francesco V, Giorgio F, Hassan C, Manes G, Vannella L, Panella C, et al. Worldwide H. Pylori antibiotic resistance: a systematic. J Gastrointestin Liver Dis. 2010; 19: 409-14.

[8] Ghotaslou R, Leylabadlo HE, Asl YM. Prevalence of antibiotic resistance in Helicobacter pylori: a recent literature review. World J Methodol. 2015; 5: 164.

[9] O'connor A, Lamarque D, Gisbert JP, O'morain C. Treatment of Helicobacter pylori infection. Helicobacter. 2017; 22: (S1).

[10] Seck A. Maladie ulcéreuse gastroduodénale et Helicobacter pylori: Profil de sensibilité des souches de Hp isolées à Dakar. Thèse Pharm, Dakar p. 110. 2001.

[11] Sherif M, Mohran Z, Fathy H, Rockabrand DM, Rozmajzl PJ, Frenck RW. Universal high-level primary metronidazole resistance in Helicobacter pylori isolated from children in Egypt. J Clin Microbiol. 2004; 42: 4832-34.

[12] Chaabouni H, Bouzid H, Masmoudi A, Cheikh I, Fendri C, Ben Ammar A. Evaluation in vitro de la résistance primaire de Helicobacter pylori aux antibiotiques chez les ulcéreux duodénaux tunisiens. SNFGE. 2004.

[13] Kouitcheu Mabeku LB, Eyoum Bille B, Tepap Zemnou C, Tali Nguefack LD, Leundji H. Broad spectrum resistance in Helicobacter pylori isolated from gastric biopsies of patients with dyspepsia in Cameroon and efflux-mediated multiresistance detection in MDR isolates. BMC Infectious Diseases. 2019; 19: 880 .

[14] Ndip RN, MalangeTakang AE, Ojongokpoko JE, et al. Helicobacter pylori isolates recovered from gastric biopsies of patients with gastro-duodenal pathologies in Cameroon: current status of antibiogram. Trop Med Int Health. 2008; 13: 848-854.

[15] Malfertheiner P, Megraud F, O'Morain CA, Atherton J, Axon ATR, Bazzoli F, et al. Management of Helicobacter pylori infection - the Maastricht IV/Florence Consensus Report. Gut. 2012; 61: 646-64.

[16] Kouitcheu Mabeku LB, Noundjeu Ngamga ML, Leundji H. Potential risk factors and prevalence of Helicobacter pylori infection among adult patients with dyspepsia symptoms in Cameroon. BMC infectious diseases. 2018; 18: 278.

[17] Comité de l'antibiogramme de la société Française de microbiologie [CASFM]. (2014). Recommandation 2014. p. 117. www.sfm-microbiologie.org. Consulté le 11-05-2014.

[18] Clinical and Laboratory Standards Institute (CLSI). Performance standards for antimicrobial disk susceptibility tests. Wayne: CLSI document. p. M02-A12. 2015.

[19] Gisbert JP. The recurrence of Helicobacter pylori infection: incidence and variables influencing it. A critical review. Am J Gastroenterol. 2005; 100: 2083-2099.

[20] Megraud F. Resistance of Helicobacter pylori to antibiotics. Aliment Pharmacol Ther. 1997; 11 (suppl1): 43-53.

[21] Soll AH. Consensus conference. Medical treatment of peptic ulcer disease. Practice guidelines. Practice Parameters Committee of the American College of Gastroenterology. JAMA. 1996; 275: 622-629.

[22] Malfertheiner P, Bayerdorffer E, Diete U, Gil J, Lind T, Misiuna P, et al. The GU-MACH study: the effect of 1-week omeprazole triple therapy on Helicobacter pylori infection in patients with gastric ulcer. Aliment Pharmacol Ther. 1999; 13: 703-712.

[23] Kobayashi I, Murakami K, Kato M et al. Changing antimicrobial susceptibility epidemiology of Helicobacter pylori strains in Japan between 2002 and 2005. J. Clin. Microbiol. 2007; 45: 4006-4010.

[24] Boyanova L, Gergova G, Nikolov R et al. Prevalence and evolution of Helicobacter pylori resistance to 6 antibacterial agents over 12 years and correlation between susceptibility testing methods. Diagn. Microbiol. Infect. Dis. 2008; 60: 409415 .

[25] De Francesco V, Margiotta M, Zullo A et al. Prevalence of primary clarithromycin resistance in Helicobacter pylori strains over a 15 year period in Italy. J. Antimicrob. Chemother. 2007; 59: 783-785.

[26] Malekzadeh R, Mohamadnejad M, Siavoshi F, Massarrat S. Treatment of Helicobacter pylori infection in Iran: low efficacy of recommended western regimens. Arch Iran Med. 2004; 7: 1-8.

[27] Elviss NC, Owen RJ, Xerry J, Walker AM, Davies K. Helicobacter pylori antibiotic resistance patterns and genotypes in adult dyspeptic patients from a regional population in North Wales. J. Antimicrob. Chemother. 2004; 54: 435-440.

[28] Janssen MJ, Hendrikse L, de Boer SY et al. Helicobacter pylori antibiotic resistance in a Dutch region: trends over time. Neth. J. Med. 2006; 64: 191-195.

[29] Storskrubb T, Aro P, Ronkainen J et al. Antimicrobial susceptibility of Helicobacter pylori strains in a random adult Swedish population. Helicobacter. 2006; 11: 224-230.

[30] Boyanova L, Mitov I. Geographic map and evolution of primary Helicobacter pylori resistance to antibacterial agents. Expert Rev Anti Infect Ther. 2010; 8: 59-70.

[31] Kim JM, Kim JS, Jung HC, Kim N, Kim YJ, Song IS. Distribution of antibiotic MICs for Helicobacter pylori strains over a 16-year period in patients from Seoul, South Korea. Antimicrob. Agents Chemother. 2004; 48: 4843-4847.

[32] Van de Sande-Bruinsma N, Grundmann H, Verloo D et al.; European Antimicrobial Resistance Surveillance System Group; European Surveillance of Antimicrobial Consumption Project Group. Antimicrobial drug use and resistance in Europe. Emerg. Infect. Dis. 2008; 14: 1722-1730.

[33] ESAC Yearbook 2006. European Surveillance of Antimicrobial Consumption data www.esac.ua.ac.be/.

[34] Glupezynski Y, Megraud F, Lopez-Brea M, Andersen LP. European multicentre survey of in vitro antimicrobial resistance in Helicobacter pylori. Eur J Clin Microbiol Infect Dis. 2001; 20: 820-3.

[35] Storskrubb T, Aro P, Ronkainen J, Wreiber K, Nyhlin H, Bolling-Sternevald E, et al. Antimicrobial susceptibility of Helicobacter pylori strains in a random adult Swedish population. Helicobacter. 2006; 11: 224-30.

[36] Loivukene K, Maaroos HI, Kolk H, Kull I, Labotkin K, Mikelsaar M. Prevalence of antibiotic resistance of Helicobacter pylori isolates in Estonia during 1995-2000 in comparison to the consumption of antibiotics used in treatment regimens. Clin Microbiol Infect. 2002; 8: 598-603. 
[37] Sharara AI, Chedid M, Araj GF, Barada KA, Mourad FH. Prevalence of Helicobacter pylori resistance to metronidazole, clarithromycin, amoxicillin and tetracycline in Lebanon. Int Antimicrob Agents. 2002; 19: 155-158.

[38] Hung K-H, Sheu B-S, Chang W-L, Wu H-M, Liu C-C, Wu J-J. Prevalence of primary fluoroquinolone resistance among clinical isolates of Helicobacter pylori at a University Hospital in Southern Taiwan. Helicobacter. 2009; 14: 61-65.

[39] Chang WL, Sheu BS, Cheng HC, Yang YJ, Yang HB, Wu JJ. Resistance to metronidazole, clarithromycin and levofloxacin of Helicobacter pylori before and after clarithromycin-based therapy in Taiwan. J. Gastroenterol. Hepatol. 2009; 24: 12301235 .

[40] Chisholm SA, Teare EL, Davies K, Owen RJ. Surveillance of primary antibiotic resistance of Helicobacter pylori at centres in England and Wales over a six-year period (2000-2005). Euro Surveill. 2007; 12: E3-E4.

[41] Pereyra LV, Gorordo Ipiña RC, Berruezo FA, Amieva CA, García ME, Bottiglieri MT. Sensibilidad a los antimicrobianos de aislamientos de Helicobacter pylori aislados de lesiones gástricas. Rev Argent Microbiol. 2017; 49: 153-157.

[42] Otth L, Wilson M, Fernández H, Otth C, Toledo C, Cárcamo V, et al. Isolation of Helicobacter pylori in gastric mucosa and susceptibility to five antimicrobial drugs in Southern Chile. Braz J Microbiol. 2011; 42: 442-447.

[43] González CC, García CA, Daroch MF, Kawaguchi PF, Solar $\mathrm{RH}$, Rivera FN, et al. Susceptibilidad in vitro de cepas de Helicobacter pylori: aislamiento de cepas resistentes a claritromicina. Rev Méd Chile. 2001; 129: 643-646.

[44] Lang L, Garcia F. Comparison of E-test and disk diffusion assay to evaluate resistance of Helicobacter pylori isolates to amoxicillin, clarithromycin, metronidazole and tetracycline in Costa Rica. Int J Antimicrob Agents. 2004; 24: 572-577.

[45] Torres J, Camorlinga-Ponce M, Perez-Perez G, Madrazo-De la Garza A, Dehesa M, Gonzalez-Valencia G, et al. Increasing multidrug resistance in Helicobacter pylori strains isolated from children and adults in Mexico. J Clin Microbiol. 2001; 39: $2677-2680$. 